\title{
THE EFFECT OF MOISTURE ON THE MECHANICAL PROPERTIES OF COMPACTED EXFOLIATED VERMICULITE
}

\author{
Soufiane BELHOUIDEG, Manuel LAGACHE \\ Université de Savoie, Laboratoire SYMME, BP 80439, Annecy le Vieux Cedex, F74944 France
}

Received 08 April 2014; accepted 23 October 2014

\begin{abstract}
Vermiculite refers to a small group of minerals resembling the lamella structure of the micas. Its can exfoliated chemically or thermally. Exfoliated vermiculite may be compressed and used in expanding gaskets; seals... The mechanical properties of compacted exfoliated vermiculite (CEV) strongly depend on the moisture. In this paper, the mechanical property of CEV is investigated by compression test, performed on samples under different levels of relative moisture. The compression tests are performed on samples respectively in longitudinal and transverse directions with respect to compaction axis. When comparing the mechanical property of CEV between longitudinal and transverse directions, an anisotropic behaviour is found in elastic modulus. As the relative moisture increases, the elastic modulus, failure stress and elastic recovery decrease.
\end{abstract}

Keywords: vermiculite, mechanical properties, compression test, yield pressure, moisture effects, compacted exfoliated clay.

\section{Introduction}

In recent years, argillaceous material has spurred considerable interest in the sealing industry (Sealing Technology 1998, 2003, 1997). Partly because of their potential for large range of temperature and pressures uses compared to standard sealing structures, as elastomers. Vermiculite represents an interesting alternative to asbestos and to exfoliated graphite for high temperature sealing applications. Indeed, because of its chemical and thermal stability, many applications, as high temperatures and high pressures sealing, are possible. The vermiculite material is a hydrated magnesium aluminum silicate. This media has an argillaceous structure made by the stacking of two types of flakes. Moreover, the vermiculite could be subjected to thermal or chemical exfoliation to obtain expanded material. From the compaction of exfoliated vermiculite, it could result a porous material with very low permeability, good mechanical properties, chemical and thermal stability.
The mechanical behaviour of clays is very sensitive to moisture. A number of experimental investigations have been performed for various clays in partially saturated conditions (Andra 2005; Bemer et al. 2004; Chiarelli et al. 2003; Escoffier 2002; Fityus, Buzzi 2009; Hoxha et al. 2007; Valès et al. 2004). These previous works generally show that the macroscopic failure stress decreases and the clay become more ductile when the moisture increases. The elastic modulus also decreases with moisture. Such effects of moisture are inherently related to the modification of microstructure in clayey rocks (Bornert et al. 2010; Homand et al. 2006; Robinet 2008). In nanometric scale, the drying and wetting process may modify distance between clay sheets leading to modification of mechanical properties of clay aggregates (Robinet 2008). However, one of difficulties in the realization of mechanical tests on partially saturated clays is to obtain a uniform saturation distribution inside samples during a reasonable duration. Indeed, due to the low permeability of clays, 
the desaturation and resaturation processes are generally very slow and need long time depending on the size of samples.

The stability of clays is largely affected by moisture. An increase in the moisture modifies the consistency of the clay and thus its mechanical properties. The moisture seems to be a crucial parameter for study of the mechanical behavior of compacted exfoliated vermiculite (CEV). The samples of CEV hydrate rapidly when exposed to atmospheric air. Nguyen (Nguyen 2012) studied rehydration samples of CEV in atmospheric air (relative humidity $~ 60 \%$ ) by measuring, according to time, the variation of the samples mass and dimensions. This study showed that:

- Adsorption of atmospheric moisture leads to swelling of the samples and an increase of the mass about $1.3 \%$.

- The swelling of the samples is anisotropic: noting that the longitudinal swelling is dominant over the transverse swelling, with respect to compaction axis.

- Samples hydration is a reversible phenomenon.

- Adsorbed water is only located in the open pores.

- The moisture increases the apparent density from 2.12 to 2.18 .

In this study, the mechanical properties (Young's modulus, elastic recovery...) of the CEV samples will be determined at different moisture $(20 \%, 40 \%$ and $90 \%)$. Test used is the compression test. The first part of this series is devoted to a general presentation of the materials which have been used and the elaboration of the CEV samples. The procedure of compression test is presented. Results of systematic measurements of mechanical properties at different moisture are gathered in second section.

\section{Experimental procedures}

\subsection{Preparation process}

The vermiculite used in this study is exfoliated vermiculite Granutech E from China (Yuli), distributed by the Comptoir des Minéraux et de Matières Premières de Paris (CMMP). The mean size of these vermiculite particles is in the range of 0.7 to $2 \mathrm{~mm}$. In order to reduce the size of these particles, different treatments were tested by Nguyen (Nguyen 2012). The ultrasonic irradiation in $\mathrm{H}_{2} \mathrm{O}_{2}$ (hydrogen peroxide) leads to reduce the particle size. So, for treatment of acceptable time (5h), the measured average particle size is about $2.0 \mu \mathrm{m}$ (Nguyen 2012). It is important to underline that the particle size of vermiculite, used in this study, is very different from the size of the vermiculite particles commonly encountered.

The samples were prepared by compaction the powder of vermiculite at room temperature $\left(20^{\circ} \mathrm{C}\right)$. Vermiculite powder exchanged with lithium $\left(\mathrm{Li}^{+}\right)$ (Nguyen 2012) was used in this study.

The vermiculite powder was put into a cylindrical mold. The powder was compacted by a moving piston with a controlled pressure (Fig. 1). The pressure applied with the piston was about $80 \mathrm{MPa}$. The temperature could be fixed during the holding pressure time.

To obtain cylindrical samples with a diameter of $8 \mathrm{~mm}$ and a height about $4 \mathrm{~mm}$ (Fig. 2), a quantity of exfoliated vermiculite powder (490 mg) was compacted at desired pressure and at room temperature during $30 \mathrm{~min}$.

For our purpose of measuring the influence of moisture on the mechanical properties, the CEV samples were performed at three moisture ratio (ambient moisture). The method used to obtain controlled moisture is the use of chemical solutions. These chemical solutions allow to impose constant moisture.

a)

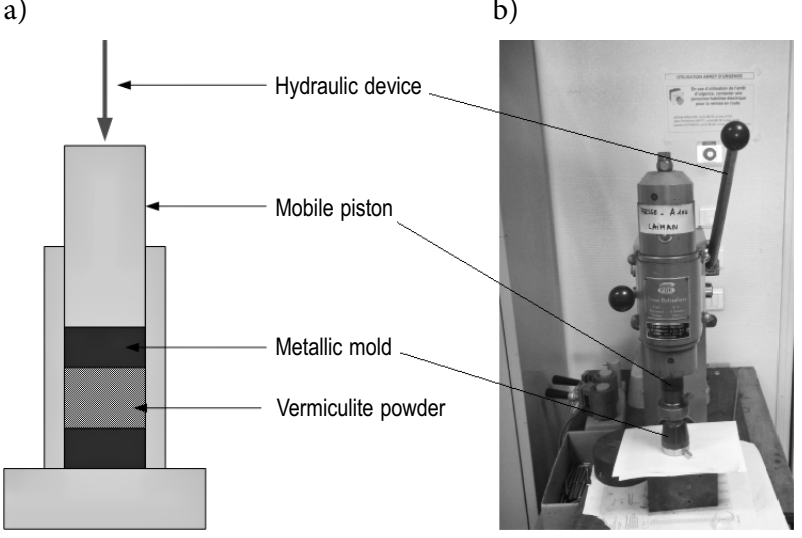

Fig. 1. Preparation process of the CEV samples: (a) schematic of the implementation tool (b) picture of the implementation tool

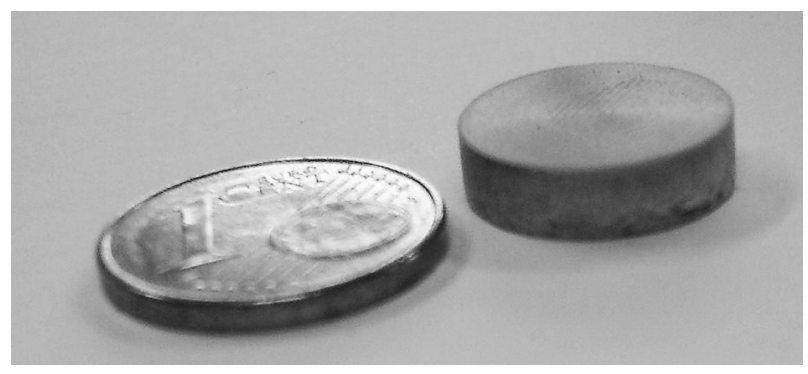

Fig. 2. CEV sample 
The samples are placed in a hermetic container with the chemical solution (see Fig. 3). Before placing the CEV samples in containers at different moisture and different chemical solution, the samples were dried at $80{ }^{\circ} \mathrm{C}$ during 24 hours to limit the initial quantity of adsorbed water. To perform the mechanical tests, a set of 32 samples were prepared in the laboratory.

a)

b)

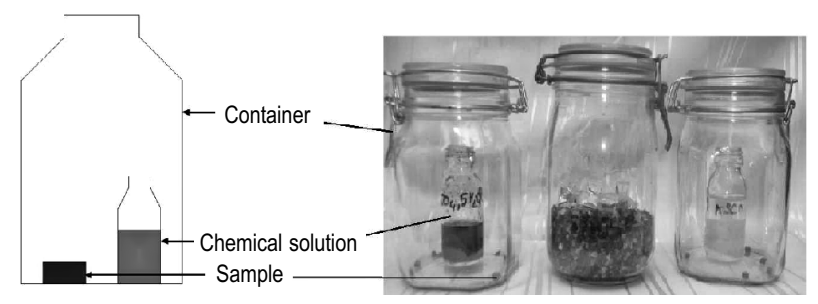

Fig. 3. CEV samples at controlled moisture: (a) schematic of the implementation tool (b) picture of the implementation tool

The chemical solutions used for the solutions are:

- Silica gel $\mathrm{Si}(\mathrm{OH})_{4}$ : moisture ratio $\approx 20 \%$.

- Potassium thiocyanate KCNS: moisture ratio $\approx$ $40 \%$.

- Copper sulphate $\mathrm{CuSO}_{4:}$ moisture ratio $\approx 90 \%$.

To prepare two solutions of copper sulphate and potassium thiocyanate, the dosage was performed with successive additions of product until a sustainable saturation. The CEV samples and chemical solutions were stored in containers during 7 days for the total stabilization of system (see Fig. 3).

\subsection{Procedure of compression test}

Because of the brittle behavior of such materials and the use of CEV in seals applications, the samples were tested in compression. The uni-axial compressive stress-strain behaviors were performed by using an EPLEXOR ${ }^{\circledR} 500$ testing machine at room temperature $\left(20^{\circ} \mathrm{C}\right)$ (Fig. 4). The tests were conducted under strain control, with a strain speed of $0.6 \% / \mathrm{min}$. Five cycles were carried out for each sample and the elastic modulus were the average (average values of five cycles) of the loaded and unloaded elastic modulus. Moreover, some tests were recorded with a camera PULNIX TM-4200 GE. These images enable to track the strain evolution of the sample. The synchronization between the measures (force, displacement...) and saving images allows to provide an image for different loading states. About thirty samples were tested (10 for each series).

The capacity of the EPLEXOR ${ }^{\oplus} 500$ machine is limited to $500 \mathrm{~N}$, and to achieve the highest possible stress, it was necessary to reduce the surface of the loaded area. The cutting of these samples was carried out from cylindrical samples using a Leica RM2165 microtome (Fig. 5).

The samples have a parallelepiped shape, as shown in Fig. 5. The loading/unloading were performed in the transverse direction (along the 1 or 2 axis) and the longitudinal direction (according to the axis 3 ) of the samples, as shown in Fig. 6. The axis 3 is the direction of compaction of the sample. The mechanical properties measured are: the longitudinal Young modulus, the transverse Young modulus, the failure stress and the elastic recovery of the samples.

Medium, intermediate, and high humidity levels were selected to estimate the influence of this moisture over a wide range. Moreover, for our specific use of this material as gaskets, the moisture ratio varies between about $20 \%$ and $90 \%$. a)

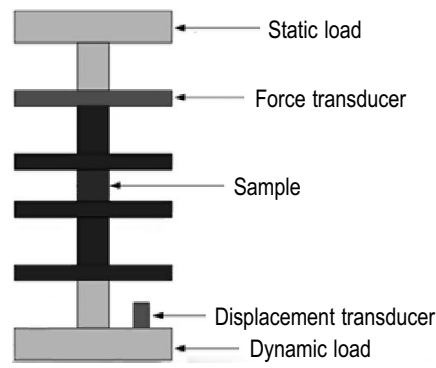

b)

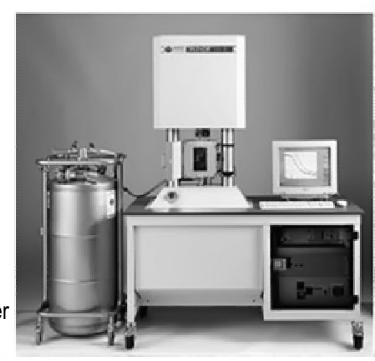

Fig. 4. EPLEXOR 500 machine: scheme (a) and picture of EPLEXOR (b)

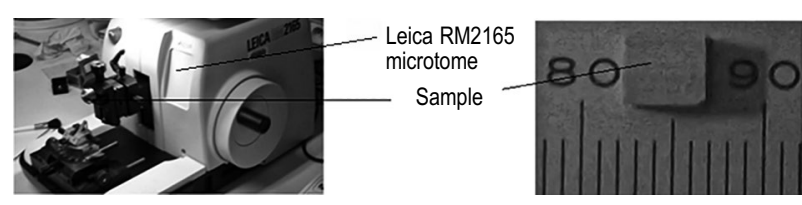

Fig. 5. Sample cut with Leica RM2165 microtome

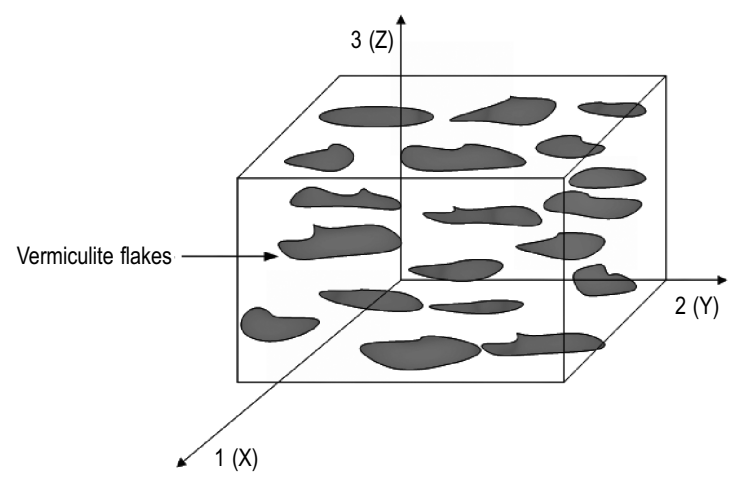

Fig. 6. Definition of the coordinate system 


\section{Experimental results and discussion}

\subsection{Young modulus determination}

Young's modulus is measured during loading/unloading test according to the three directions 1, 2 and 3 (see Fig. 7). Young's modulus is estimated from the slope of the loading or unloading curves. For a perfectly elastic material, it has the same slope as in loading and unloading configurations. The CEV materials have significantly different elastic modulus during loading and unloading. The slope of the linear part of the loading and unloading curve is taken as the loaded and unloaded elastic modulus, as shown on the Figure 7. The unloaded elastic modulus is noticeably greater than the loaded elastic modulus.

Figure 7 shows a representative stress-strain curve of CEV samples. All curves exhibit a characteristic compressive behavior of porous materials. This behavior has three steps: the initiation of strain, the elastic stage, and a quasi-platform stage that appears. With a close look at the initial elastic stage, it can be noticed that CEV materials exhibit a nonlinear stressstrain behavior. The reason is that the strain consists of the flakes elastic strain and the "structural strain", and these two types of coupled strain lead to a nonlinear behavior. On the other hand, loading/unloading cycles indicates significant stress-strain hysteresis, suggesting damping and energy absorption capacities.

The effects of vermiculite flakes, on the macroscopic behavior, are complex. Indeed, these flakes are oriented in any direction but with a Gaussian distribution, perpendicular to the compaction axis. So the flakes undergo compression, bending and torsion. It is obvious that the joints (joints between flakes cluster) in this material play an important role in terms of the "structure effect". The macroscopic behavior may result from the friction between the flakes and/or from the irreversible flakes rearrangements.

Longitudinal and transverse Young modulus $\left(E_{L}\right.$, $E_{T}$ ) changes according to moisture ratio are shown in

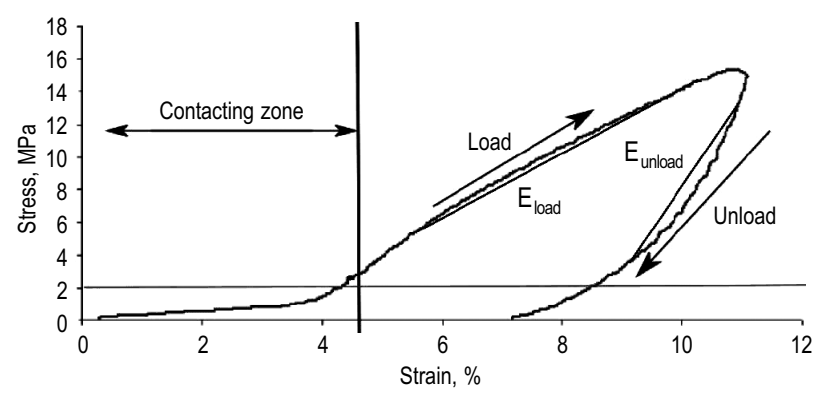

Fig. 7. Experimental curve of the load-unload test

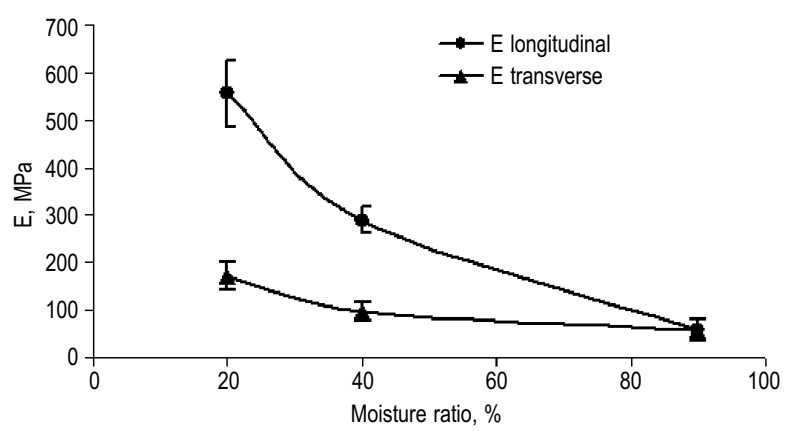

Fig. 8. Young's modulus variation according to moisture ratio

Figure 8. These curves show the influence of moisture on the elastic modulus of CEV, when the moisture ratio increases, the Young's modulus decreases. It noticed that the moisture tends to decrease the anisotropic character of the material. When the sample moves from dry environment to environment with high moisture (moisture of about 90\%), the Young's modulus decreases by $89 \%$ in the longitudinal direction and $65 \%$ in the transverse direction. Longitudinal and transverse Young modulus are $\left(E_{L}=560 \mathrm{MPa}\right.$, $\left.E_{T}=170 \mathrm{MPa}\right)$ for a moisture ratio of $20 \%$, and $\left(E_{L}=\right.$ $60 \mathrm{MPa}, E_{T}=60 \mathrm{MPa}$ ) for a moisture ratio of $90 \%$.

Table 1 summarizes the anisotropy ratio $\left(\alpha_{E}=E_{L} /\right.$ $E_{T}$ ) of the Young's modulus as a function of moisture. When the moisture increases, the CEV tends to become isotropic. Among many factors related to desaturation and resaturation process, the suction plays an essential role due to the small size of CEV pores. At macroscopic scale, the suction generates not only an overall confining effect but also compaction or swelling of bedding planes. As a consequence, the desaturation intensifies the role of structural anisotropy on the macroscopic behaviour of CEV.

Table 1. Anisotropy ratio of Young's modulus ( $\mathrm{E}_{\mathrm{L}}$ longitudinal Young's modulus and $\mathrm{E}_{\mathrm{T}}$ transverse Young's modulus)

\begin{tabular}{|c|c|c|c|}
\hline Moisture ratio & $20 \%$ & $40 \%$ & $90 \%$ \\
\hline$\alpha_{E}=E_{L} / E_{T}$ & 3.2 & 3.0 & 1.0 \\
\hline
\end{tabular}

Ibrahim (Ibrahim 2008) has studied the influence of moisture on the mechanical properties of rocks (Callovo Oxfordian clay). When the moisture moves from $40 \%$ to $90 \%$, the longitudinal Young's modulus decreases by $59 \%$ and transverse Young's modulus decreases by $61 \%$. This study showed the negative effect of moisture on the mechanical properties. Ibrahim (Ibrahim 2008) concluded that more clay is humid, the 
more can be considered isotropic. The results obtained by (Ibrahim 2008) are consistent with the results obtained in this work.

\subsection{Failure stress}

During compression tests, crack appeared and propagated in the material, as shown in Figure 9b. two situations are distinguished:

- Cracks appear away from the sample edges. The corresponding stress can be representative of the failure stress of the material (Fig. 9c). The corresponding stress is the failure stress.

- Cracks appear at the sample edge (Fig. 9d): these cracks due to defects created during the cutting of samples. These samples are not considered for the evaluation of failure stress of the material.

Figure 10 shows the variation of the failure stress versus moisture ratio. When the moisture increases, the failure stress decreases in the longitudinal and transverse directions. In addition, it was found that the failure stress ratio $\left(\frac{\sigma_{L_{-} \text {rupt }}}{\sigma_{T_{-} \text {rupt }}}\right.$, where $L$ and $T$ respectively denote the axial and transverse direction) varies from 3.5 to 2.5 when the moisture ratio varies from 20 to $90 \%$. This curve confirms the previous remark about the tendency of material to be more isotropic when the moisture increases. When the CEV sample moves from dry environment to environment with high moisture (moisture of about 90\%), the failure stress decreases by $83 \%$ in the longitudinal direction and by $77 \%$ in the transverse direction. Longitudinal and transverse failure stress are $\left(\sigma_{L_{-} \text {rupt }}=29 \mathrm{MPa}, \sigma_{T_{-} \text {rupt }}=8 \mathrm{MPa}\right)$ for a moisture ratio of $20 \%$, and $\left(\sigma_{L_{-} \text {rupt }}=5 \mathrm{MPa}, \sigma_{T_{-} \text {rupt }}=\right.$ $2 \mathrm{MPa}$ ) for a moisture ratio of $90 \%$.

\subsection{Elastic recovery}

For specific applications, one of the requirements is a high elastic recovery. To determine this property, the thickness variation during the compression test (loading/unloading) was measured. Figure 11 illustrates a

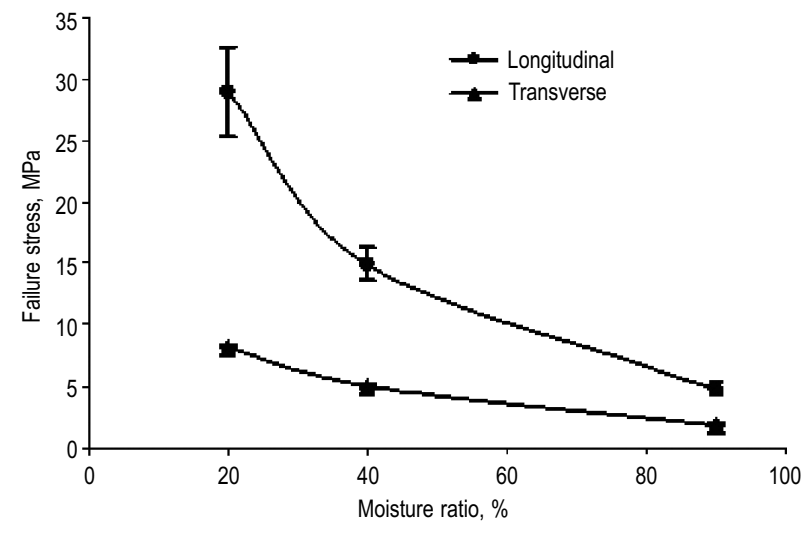

Fig. 10. Failure stress variation according to moisture ratio

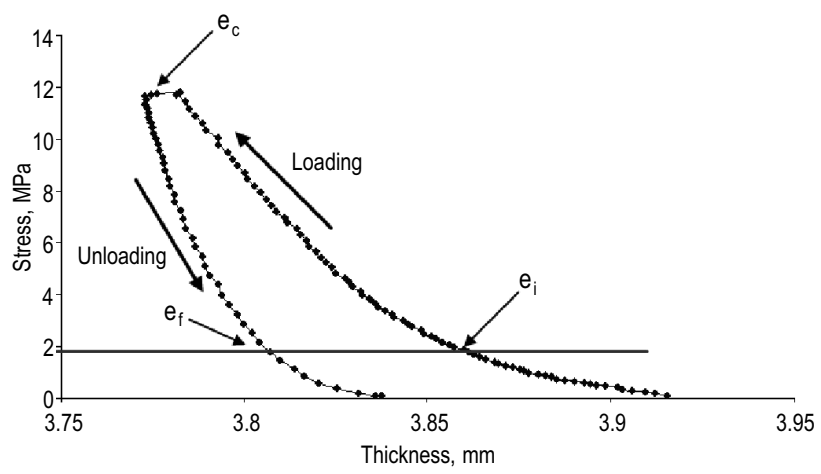

Fig. 11. Experimental compression curve and definition of parameters for elastic recovery determination

loading/unloading test curve and the specific parts used for the calculation of the elastic recovery.

According to ASTME-36, the elastic recovery $r_{e}$ is defined with the following relation (1):

$$
r_{e}=\frac{e_{f}-e_{c}}{e_{i}-e_{c}},
$$

where $e_{i}$ - initial thickness of the sample; $e_{c}$ - thickness under maximum stress; $e_{f}$ - final thickness after release of the load.

To minimize the measurement incertitude of elastic recovery, the initial and final thicknesses were measured for a stress of $2 \mathrm{MPa}$, as shown in Figure 11. This allows to start the measurement when the sample surfaces are in contact with the sample holder and not with few asperities.

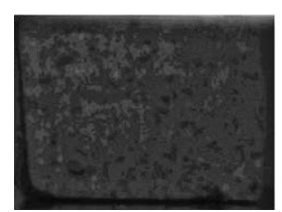

a) Initial sample

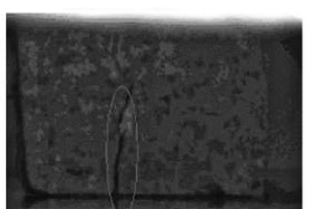

b) Apparition of crack

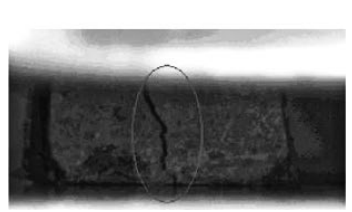

c) Rupture in the middle

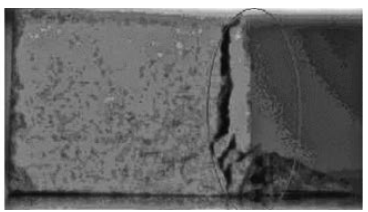

d) Rupture at the edge of sample

Fig. 9. Apparition configurations of cracks 


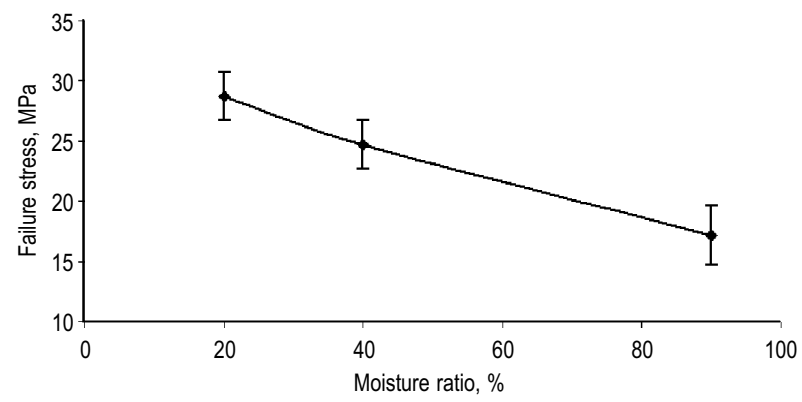

Fig. 12. Elastic recovery variation according to moisture ratio

Figure 12 shows the variation of the elastic recovery of sample according to moisture ratio. Elastic recovery is reduced by the presence of moisture. It varies from $28.7 \%$ in dry environment to $17 \%$ in an environment with high moisture (moisture of about 90\%).

In general, the moisture has a significant and negative effect on the main CEV properties.

\section{Conclusions}

This paper presents a mechanical characterization of CEV samples at different moisture ratio. Compression tests have been performed on the CEV samples for different values of moisture.

The variations of elastic modulus, failure stress and elastic recovery have been investigated for two principal loading/unloading orientations longitudinally and transversally to the compaction axis. It is found that the mechanical properties of the CEV are strongly influenced by moisture. The main mechanical properties of CEV were substantially changed by the moisture. The rigidity, the compression strength decreased significantly when the moisture ratio increased (from 20\% to 90\%). Furthermore, the degree of anisotropy of the CEV samples decreased when humidity increased. It is crucial to protect the CEV samples from moisture so that theperformance of CEV samples does not degrade.

\section{Acknowledgements}

This work was supported by the French Research National Agency (ANR) through the Célajoas project (ComposÉs LAmellaires pour les JOints en Applications Sévères).

The authors would like to thank Mr. Thierry ALONSO from the 3SR laboratory (Sols, Solides, Structures, Risques) - University of Grenoble, for his help during the mechanical tests.

\section{References}

Andra. 2005. Referentiel du site Meuse-Haute Marne. Report. Australian National Drag Racing Association.

Bemer, E.; Longuemare, P.; Vincké, O. 2004. Poroelastic parameters of Meuse/Haute Marne argillites: effect of loading and saturation states, Applied Clay Science 26(1-4): 359-366. http://dx.doi.org/10.1016/j.clay.2003.12.012

Bornert, M.; Vales, F; Gharbi, H.; Nguyen, M. D. 2010. Multiscale full-field strain measurements for micromechanical investigations of the hydromechanical behaviour of clayey rocks, Strain 46(1): 33-46.

http://dx.doi.org/10.1111/j.1475-1305.2008.00590.x

Chiarelli, A. S.; Shao, J. F.; Hoteit, N. 2003. Modeling of elastoplastic damage behaviour of a claystone, International Journal of Plasticity 19(1): 23-45. http://dx.doi.org/10.1016/S0749-6419(01)00017-1

Escoffier, S. 2002. Caractérisation expériementale du comportement hydromécanique des argillites de Meuse/Haute Marne. INPL Nancy, France.

Fityus, S. G.; Buzzi, O. 2009. The place of expansive clays in the framework of unsaturated soil mechanics, Applied Clay Science 43(2): 150-155. http://dx.doi.org/10.1016/j.clay.2008.08.005

Homand, F.; Shao, J.; Giraud, A.; Auvray, C.; Hoxha, D. 2006. Pétrofabrique et propriété mécaniques des argilites, Comptes Rendus Geoscience 338(12-13): 882-891. http://dx.doi.org/10.1016/j.crte.2006.03.009

Hoxha, D.; Giraud, A.; Homand, F.; Auvray, C. 2007. Saturated and unsaturated behaviour modelling of Meuse-Haute/ Marne argillite, International Journal of Plasticity 23(5): 733-766. http://dx.doi.org/10.1016/j.ijplas.2006.05.002

Ibrahim, N. 2008. Caractérisation des propriétés mécaniques des géomatériaux par technique de micro indentation. Université de Lille, Lille.

Nguyen, N. A. 2012. Elaboration et caractérisation de matériaux d'étanchéité à base de vermiculite. Université de Grenoble, France.

Robinet, J. C. 2008. Mineralogie, porosite et diffusion des solutes dans l'argilite du Callovo-Oxfordien de bure (meuse/hautemarne, France) de l'echelle centimetrique a micrometrique. University of Poitiers, France.

Sealing Technology 1997. Vermiculite - the high temperature sealing material of the future?, Sealing Technology 1997(46): 8-9.

Sealing Technology 1998. Vermiculite gaskets to beat the heat, Sealing Technology 1998(55): 5.

Sealing Technology 2003. Production of vermiculite foil, Sealing Technology 2003(3): 14.

Valès, F; Nguyen, M. D.; Gharbi, H.; Rejeb, A. 2004. Experimental study of the influence of the degree of saturation on physical and mechanical properties in Tournemire shale (France), Applied Clay Science 26(1-4): 197-207. http://dx.doi.org/10.1016/j.clay.2003.12.032 
Soufiane BELHOUIDEG is PhD in mechanical and materials at SYMME Laboratory (SYstems and Materials for Mechatronics), France. His work focuses on mechanics of materials and structures, modeling of mechanical behavior of materials, modeling of heterogeneous media, finite element method, computational mechanics and composite materials.

Manuel LAGACHE is an associate professor at Savoie Mont Blanc University - France, where he teaches mechanics and mathematics. His work focuses on mechanical engineering, materials engineering, applied and computational mathematics, finite element method, fluid mechanics, composites and nanofabrication. 